\title{
Application of GIS in temperature management
}

\author{
Gholam Reza Janbaz Ghobadi ${ }^{1}$ and Mehrdad Ahmadi Kamarposhti ${ }^{2 \star}$ \\ ${ }^{1}$ Department of Agriculture, Islamic Azad University, Jouybar Branch, Jouybar, Iran. \\ ${ }^{2}$ Department of Electrical Engineering, Islamic Azad University, Jouybar Branch, Jouybar, Iran. \\ m.ahmadi@jouybariau.ac.ir*
}

\begin{abstract}
In this paper, we introduce GIS as an enabled tool and efficient technology in drawing and creating data base for collecting, saving, recovering and analyzing information in temperature management.
\end{abstract}

Keywords: Computer, GIS, information, climate.

\section{Introduction}

In recent decades, because of computer technologies development, Geographic Information System (GIS) makes possible to keep reference land data and to combine different data set, effectively. GIS technology enables to depict events, predicting results and preparing the maps clearly.

\section{Use of geographic information system in temperature management}

Use of GIS in climatology is quickly developing. A big center of producing climate data such as Nova is the pioneers of GIS application in climatology. The samples of climate studies had practical and operational using GIS For an example, Dyras et al. (2003) have made a model for predicting and informing road ice bounds in Europe. Baban and Parry (2001) used GIS for establishing wind turbines.

\section{Fig. 1. A type of real world modeling}

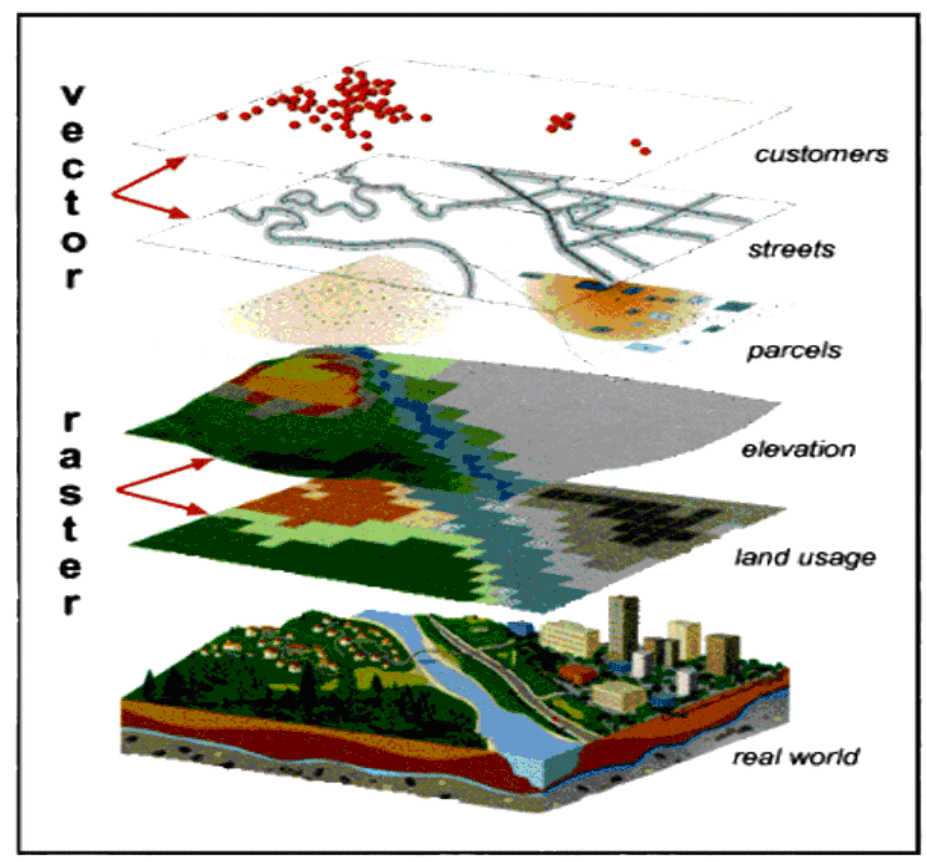

Thermal climatology in rural and urban areas using a GIS was the subject of investigation (Bradley et al., 2002). Daly et al. (2000) presented a model for finding the middle of climate variables and provided temperature and rainfall maps of U.S.A with geographical segregation degree change effects on ecosystems using GIS. Eatherall (1997) studied modelling climate change impacts on ecosystems using linked models and a GIS

El Garouani et al. (2000) showed the use of GIS for estimating real evaporation and transpiration at a regional scale. Investigation of drought through digital analysis of satellite data and GIS was the topic by Ghosh (1997). Mapping temperature and rain fall with polynomial regression and a digital elevation was performed by Goodale et al. (1998). Prudhomme (1999) investigated the geographical pattern of extreme rainfalls in a mountainous region. Climate change impacts on the hydrologic resources of Europe were investigated by Strzepek and Yates (1997). Zakarin and Mirkarimova (2000) investigated the mathematical modeling of urban air pollution of the basis of GIS. Vandenbergh et al. (1999) have studied GIS approach for the setting of solar thermal power plants.

\section{Methods}

\section{Geographic data models}

We can use GIS and computers for real world directly. Because, digital computers work on the basis of numbers or characters (kept in them as two-character numbers). First we should collect data and then the process of compressing geographic scope, structure, geophysical features or other each feature of the earth is performed. It is done in typical models so that they are accessible for the computer.

Each map of geology is a typical model because simple scope is part of the real world which is viewed from the view at a field geologist. The components of noted model are geographic problem which are estimated as the same independent entities of real world which are showed on the map by means of graphic symbols.

All of the geographical data models are formed from
Popular article

CIndian Society for Education and Environment (iSee)
"Use of GIS in climatology" http://www.indjst.org
Ghobadi \& Kamarposhti Indian J.Sci.Technol. 
separate geographic problems such as points, lines, areas, densities and levels. These geographic problems are determined by geographical and non-geographical features. Digital description at problems and their features consist of geographical data set. Fig. 1 shows a type of real world modeling.

\section{Input and output data}

A useful geographic information system should be able to receive and produce information effectively. The functions of data output and input are concepts by which a GIS can communicate with the outside world.

\section{The data which can be entered into a GIS consists of two} kinds:

1. Geographical data which shows geographic situation of problems (such as points or lines which shows geographic tools like street, lake and etc).

2. Non-geographical data which describe tool 's features such as water ss salt of a lake and or information such as name of a street.

The data can be entered in to a GIS by shapes. The out put of data is a process which information of GIS is given suitably for user. The data exit as one of three following formats:

1. Hard copy: permanent showing such as the information on paper, photographic film and the same cases.

2. Soft copy. showing on the computer screen.

3. Electronic: The out put in the electronic format consists of computer files.

\section{The processes of establishing GIS in project format}

Creating and establishing of GIS in the format of a project consists of data input, data management, analysis, data manipulation and finally data output.

1. Data input. The component of data input represents land data as the paper maps, tables of described information, electronic files and their information air photographs and or satellite pictures.

2. Data management: It consists of functions for saving, keeping and recovering the existing information in data base.

3. Data manipulation \& analysis: This consists of a set of activities which performed by software, hardware and user for preparing and processing the data for next stages.

4. Data output: Usable output functions are determined on the basis of user 's requirements. Hence, output data is given by different shapes such as map, tables either as hard copy or soft copy.

In fact, GIS provides activity abilities for collecting, entering, processing, transformation, visualization, combination, searching, analysis, modeling and the out put of all geographical data.

\section{Climate data manipulation in GIS}

The basis of climate data is the measures which are performed in pre-determined time intervals by air observation stations. The measured quantities of climate elements are attributed only to the measuring points. Because climate elements change with the time and place, the measured quantities change quickly or slowly as linear or non- linear and lose the capability as place. We can $t$ recognize the climate of place by a few air observations in a short. Such is the case, we can $t$ also identity the borders of climate areas by investigation of few air observation station unless, the changes of climate elements of distant stations are cleared using the methods and new and classic tools of GIS. Using maps algebra, the main core of GIS in climatology, we can produce new maps. For e.g., consider following functions which pressure square convert to Gradient Square and the map of low pressure and high pressure systems.

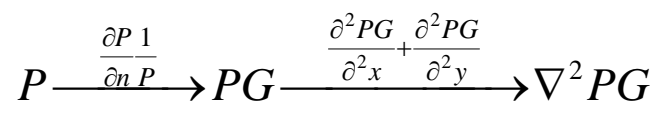

The maps of pressure gradient and surfer systems are calculated and drawn using these environmental relations (Fig. 2). We can mention a lot of examples of this kind of application. There is a common processes in GIS by which we can study the feature of a climate element on the basis of it s distance from a certain geographic phenomenon. Climate causes variability and itself changeable. Investigating these differences and variability in time-dominant is performed by testing the climate elements. Investigating these changes in placedominant is practiced by searching the place of a certain phenomenon in a certain period time.

We can show the results of processes as various kinds lonely separating from kinds of processes which is

Fig. 2. Convert process of map of pressure into map of pressure gradient \& the map of surfer systems

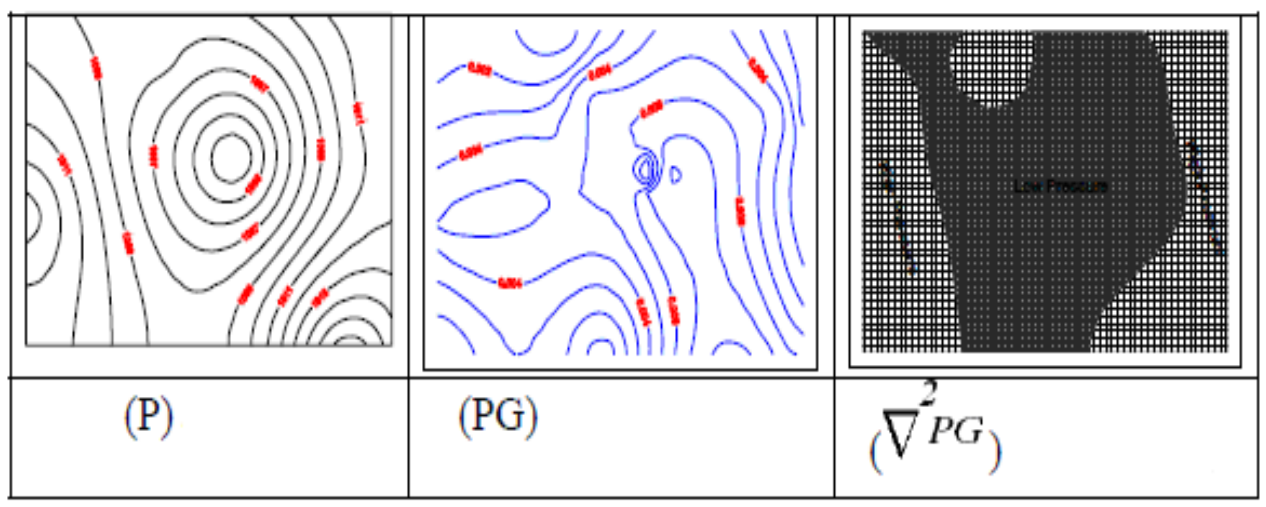

"Use of GIS in climatology" http://www.indjst.org
Ghobadi \& Kamarposhti Indian J.Sci.Technol. 
resulted in producing new information of primitive data, equal maps, extending maps, vector maps, shading maps, three-dimensional maps are the examples of the ways of information showing in GIS. In equal maps, the lines show the geographical change, of climate elements (Fig. 3).

Geographical changes of most of the climate elements have a relationship with the ruggedness of earth level. So, showing the ruggedness of earth level with a shading map as a background and showing the map of climate elements on it can create a clear understanding from the ruggedness role on the geographical structure of climate elements. Three- dimensional maps have good visual view and also help understand the spatial relations of different parts of forming climate.

Fig. 3. Illustration of speed \& air direction

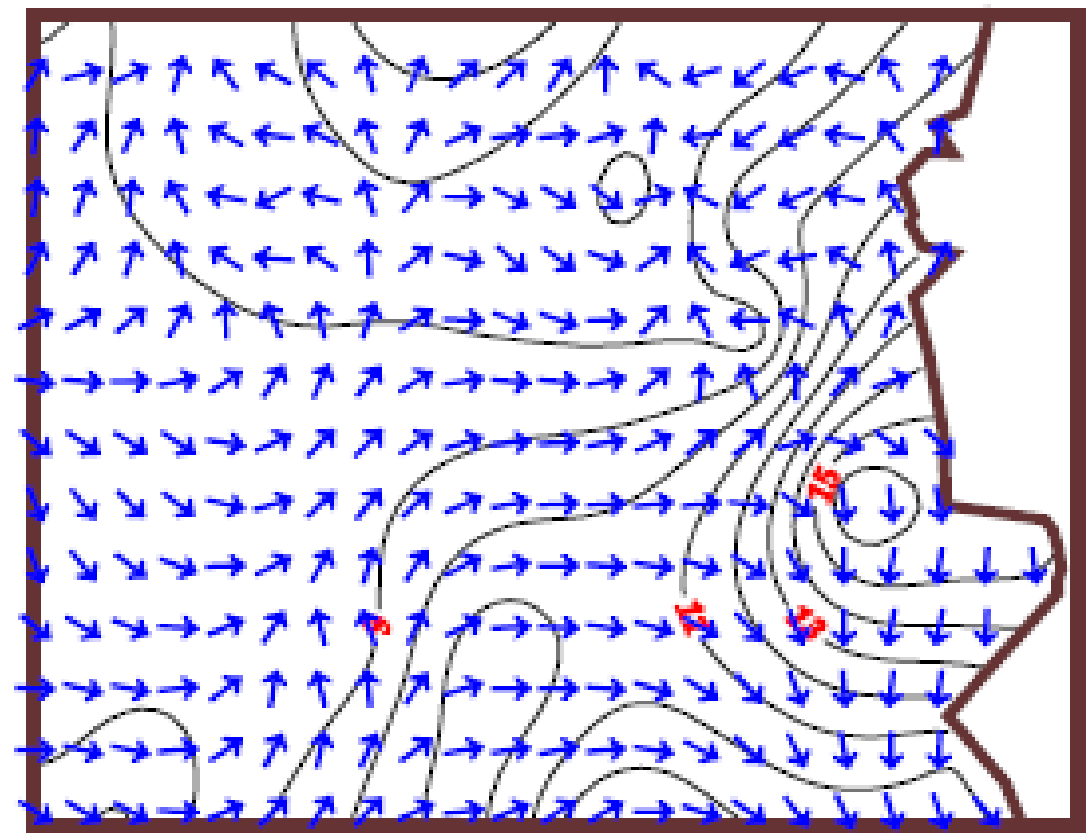

\section{Conclusion}

GIS is an enabled tool for knowing time and geographical feature of climate elements. Identifying the geographical relations, climatic pattern and climatic element, it is possible to recognize the present aspect of climate and its future feature.

\section{References}

1. Baban SMJ and Parry T (2001) Developing and applying a GIS-assisted approach to locating wind farms in the UK. Ren. Energy. 24, 59-71.

2. Bradley AV, Thornes JE, Chapman L, Unwin D, Roy $M$ (2002) Modelling spatial and temporal road thermal climatology in rural and urban areas using a GIS. Climate Res. 22, 41-55.

3. Daly C, Taylor GH, Gibson WP, Parzybok TW, Johnson GL, Pasteris PA (2000) High-quality spatial
Vol. 3 No. 4 (Apr. 2010)

ISSN: 0974- 6846

climate data sets for the United States and beyond. Trans. ASEA. 43, 1957-1962.

4. Dyras I, Dobesch H, Grueter E, Perdigao A, Tveito Ole E, Thornes John E and Van der Wel F, Bottai L (2003) The use of Geographic Information Systems in climatology and meteorology. COST 719. Meteorological Applications. 12, 1-5.

5. Eatherall A (1997) Modelling climate change impacts on ecosystems using linked models and a GIS. Climatic Change. 35, 17-34.

6. El Garouani A, Boussema MR and Ennabli H (2000) Use of the geographic information system and remote sensing data for the estimation of real evapotranspiration at a regional scale. Int. J. Remote Sensing. 21, 2811-2830.

7. Ghosh TK (1997) Investigation of drought through digital analysis of satellite data and geographical information systems. Theor. Appl. Climatology. 58, 105-112.

8. Goodale CL, Aber JD and Ollinger SV (1998) Mapping monthly precipitation, temperature, and solar radiation for Ireland with polynomial regression and a digital elevation model. Climate Res. 10, 35-49.

9. Prudhomme C (1999) Mapping a statistic of extreme rainfall in a mountainous region. Phy. Chem. of the Earth Part-B Hydrol. Oceans Atmosphere. 24, 79-84.

10. Strzepek KM and Yates DN (1997) Climate change impacts on the hydrologic resources of Europe: A simplified continental scale analysis. Climatic Change. 36, 79-92.

11. Vandenbergh $M$, Neirac FP and Turki $H$ (1999) A GIS approach for the siting of solar thermal power plants application to Tunisia. J. de Physique. 9, 223-228.

12. Zakarin EA and Mirkarimova BM (2000) GIS-based mathematical modelling of urban air pollution. J. Atmospheric Oceanic Phy. 36, 334-342. 